\title{
Discussion on Mathematics Education in Colleges and Universities Under the View of Mathematics Culture
}

\author{
Yunwen Yang \\ Hubei College of Chinese Medicine, Jingzhou, Hubei, China, 434020 \\ 179059647@qq.com

\begin{abstract}
In the course of human development, digital culture is constantly developing, and digital culture belongs to higher mathematics education, which can play a very important role in higher mathematics education. Mathematics is not only a basic subject in colleges and universities students' learning of other subjects. education for research and discussion.
\end{abstract}

Keywords: Mathematics Education in Colleges and Universities; View of Mathematics Culture

\section{高校数学教育在数学文化观视域下的探讨}

\author{
杨云雯
}

湖北中医药高等专科学校, 荆州, 湖北, 中国, 434020

179059647@qq.com

\section{摘要}

在人类的发展历程中, 数字文化也在不断地发展, 而数字文化也归属于高等数学教育, 在高等数学教 育中能够发挥出非常关键的价值, 而数学在高校中不仅仅是一门基础性学科, 学生对于数学学科的学 习, 也会影响到学生对于其他科目的学习, 而且数学信息对于学生的逻辑思维能力以及对于学生的解 决问题的能力有着非常高的要求, 如果学生在质量方面无法达到标准, 那么学生学习数学也会更加困 难，而本文就主要围绕在数学文化关系下的高校数学教育进行研究和探讨。

关键词: 高校数学教育; 数学文化观视域

\section{1. 数学文化观的形成}

就现阶段而言, 在高校教育体系中, 数学教育是一 项占据着非常重要地位的教育学科, 而在数学中学生也 能够学习到非常有利于学生的学习和生活以及学生的发 展的内容, 因此数学学习能够给予学生非常大的帮助, 而这些帮助不仅仅只限于数学领域中, 学习数学也能够 有助于学生对于其他学科的认识和理解, 只不过就现阶 段而言, 大部分学生都十分缺乏高校数学学习兴趣, 因 此在数学教育课堂上也缺乏积极性, 也因为如此, 导致 高校数学教育在数学文化观视域下的研究成为了当下数 学教育领域的重点。

\section{1 概念}

数学其实也是一种文化现象, 而数学文化指的就是 数学的发展过程, 通过对于数学的发展过程的认识和了
解, 也能够更加深入的了解数学文化, 并且, 将对数 学文化的了解融入到对数学的学习中, 加强数学能力, 而如果对数学文化有充分的了解, 就能够站在数学文 化的角度, 用数学文化的观点对待数学, 并且把握数 学的文化价值, 甚至发挥出数学的文化价值, 而数学 文化的内容不仅仅包括数学语言, 数学观点, 又或是 数学精神, 也包括数学思想和数学方法, 而除此之外, 数学教育、数学史都属于数学文化的内涵, 因此这也 代表数学学科本身是具有一定的人文成分的, 通过了 解这些人文成分也能够更加深入的了解数学, 而且从 此中也体现出了数学与社会的联系非常紧密, 只是目 前还有很多学生对于数学的认识存在误区, 认为学习 数学就是学习数学公式和数学概念, 但是实际上想要 提升综合素养和数学能力, 就十分有必要学习数学文 化。 


\section{2 特点}

数学文化与其他文化也有着共同点, 例如文化所具 备的统一性，使用统一的符号以及语言，在人类文明史 中, 数学也占据了非常重要的地位, 而数学也会跟随着 时间的流逝, 岁月的流走而不断的发展和改变的, 并且 数学文化的传播不仅仅是在课堂教学中, 在各种数学活 动中, 数学文化也能够进行传播, 并且不断的完善, 而 为了体现出数学的特点并且发挥出数学的价值, 数学教 师就必须要不断的提升自己。

\section{2. 基于数学文化观视域下的高校数学教学策 略}

表 1 基于数学文化观视域下的高校数学教学策略

\begin{tabular}{|c|c|c|c|}
\hline $\begin{array}{l}\text { 转变教学 } \\
\text { 观念, 提 } \\
\text { 高教师的 } \\
\text { 教学素质 }\end{array}$ & $\begin{array}{c}\text { 教学方式要 } \\
\text { 形式丰富 }\end{array}$ & $\begin{array}{l}\text { 对数学课 } \\
\text { 题进行想 } \\
\text { 象化处理 }\end{array}$ & $\begin{array}{c}\text { 数学教师 } \\
\text { 要多多和 } \\
\text { 其他学科 } \\
\text { 教师进行 } \\
\text { 交流 }\end{array}$ \\
\hline $\begin{array}{l}\text { 教师不可 } \\
\text { 像传统教 } \\
\text { 学一样只 } \\
\text { 给予书本 } \\
\text { 知识的讲 } \\
\text { 解, 还要 } \\
\text { 求更深层 } \\
\text { 次的教 } \\
\text { 学, 向学 } \\
\text { 生传播数 } \\
\text { 学文化。 }\end{array}$ & $\begin{array}{l}\text { 教师应该给 } \\
\text { 学生创造可 } \\
\text { 以独立思考、 } \\
\text { 独立解决问 } \\
\text { 题的环境, 在 } \\
\text { 学生身边作 } \\
\text { 为同行者, 引 } \\
\text { 导学生发现 } \\
\text { 问题和解决 } \\
\text { 问题, 真真正 } \\
\text { 正地让学生 } \\
\text { 融入数学文 } \\
\text { 化中。 }\end{array}$ & $\begin{array}{l}\text { 目前, 电 } \\
\text { 子媒体技 } \\
\text { 术十分发 } \\
\text { 达, 随着 } \\
\text { 高校的改 } \\
\text { 革, 多媒 } \\
\text { 体和互联 } \\
\text { 网技术深 } \\
\text { 入每一个 } \\
\text { 校园, 多 } \\
\text { 多利用, } \\
\text { 可将数学 } \\
\text { 形象直观 } \\
\text { 地展现给 } \\
\text { 学生。 }\end{array}$ & $\begin{array}{l}\text { 学生在学 } \\
\text { 习总会 } \\
\text { 遇到多个 } \\
\text { 学科交叉 } \\
\text { 的问题, } \\
\text { 不仅要学 } \\
\text { 好数学还 } \\
\text { 要学好其 } \\
\text { 他科目, } \\
\text { 教师可以 } \\
\text { 利用数学 } \\
\text { 和物理、 } \\
\text { 化学以及 } \\
\text { 数学和历 } \\
\text { 史之间的 } \\
\text { 关系对学 } \\
\text { 生进行引 } \\
\text { 导。 }\end{array}$ \\
\hline
\end{tabular}

\section{1 转变教学观念, 提高教师的教学素质}

高校教师不仅仅应该把数学知识教授给学生, 同时 也应该对学生传播数学文化, 让学生能够更加深入了解 数学文化, 而且传播数学文化就要求数学教学要以存在 的差异作为基础, 传播数学文化不仅仅要求教师要对学 生进行讲解, 还要求教师必须更加深入的对数学文化进 行剖析, 并且使数学文化更加深入到学生的心中。

\section{2 教学方式要形式丰富}

高校数学教学中的内容有很多都是来源于生活, 所以高校数学教学也应该由数学生活作为引导进行开 展, 只有从实际生活出发, 才能够使数学教学内容变 得更加简单和易于理解, 学生才能够更好的掌握数学 知识, 而同时如果教师能够结合生活中的案例对学生 进行讲解, 那么学生也能够得到数学能力的加强, 并 且还能够调动学生的学习积极性。

\section{3 对数学课题进行想象化处理}

大部分学生之所以不愿意接受数学学习, 又或是 数学成绩差, 主要是因为数学知识本身就十分复杂难 懂, 而难以理解也是学生学习数学的一大难关, 而且 数学学科非常注重学生的逻辑性和理解能力, 如果学 生的逻辑性和理解能力不强, 那么学生就很难全面的 掌握数学知识, 而如果学生连数学题目的问题都难以 理解, 更加难以给出正确答案, 但是通过多媒体技术, 就能够使数学知识更加直白地展现在学生的面前, 使 学生更容易接触到数学知识的内核。

\section{4 数学教师要多多和其他学科教师进行交 流}

数学学科与其他学科之间的关系也是十分紧密 的, 甚至于和某些学科是互相促进、互相成就的关系, 而学生在学习数学时, 也会遇到不同学科互相交叉的 问题, 所以教师要引导学生对其他学科的内容进行学 习, 只有对其他学科的内容都有一定的掌握, 学生才 能够学好数学, 因此这也要求所有教师应该加强和其 他学科的教师之间的交流, 寻求引导学生学习其他学 科的途径。

\section{3. 基于数学文化观视域下的高校数学教育 意义}

表 2 基于数学文化观视域下的高校数学教育意义

\begin{tabular}{|c|c|c|}
\hline 丰富教学意义 & $\begin{array}{c}\text { 展现数学文化 } \\
\text { 的内涵 }\end{array}$ & $\begin{array}{c}\text { 体现数学文 } \\
\text { 化的价值 }\end{array}$ \\
\hline
\end{tabular}




\begin{tabular}{|c|c|c|}
\hline & & \\
数学学科对于 & & 在高校数学 \\
大多数人而言 & 教育中应该 \\
都是一门非常 & 数文化的内 & 体现出数学 \\
难以理解的学 & 富, & 文化的价值, \\
科, 如果教师不 & 所以教师在对 & 并且传播数 \\
丰富和创新教 & 学生进行数学 & 学文化, 数学 \\
学手段方式, 那 & 教学时, 应该 & 文化的传播 \\
么就很容易导 & 对数学知识进 & 对于高校数 \\
致学生因为读 & 行深入的挖 & 学教育而言 \\
不懂数学而放 & 掘。 & 也是一个非 \\
弃数学学习。 & & 常关键的环 \\
& & 节。 \\
& & \\
& & \\
& & \\
& &
\end{tabular}

\section{1 有利于激发学生学习数学的兴趣}

数学学科对于大多数人而言都是一门非常难以理解 的学科, 如果教师不丰富和创新教学手段方式, 那么就 很容易导致学生因为读不懂数学而放弃数学学习, 而为 了激发学生的学习兴趣, 也为了使学生更好地掌握数学 知识, 教师就必须运用更加丰富并且有趣的教学方式, 激发学生的学习兴趣。

\section{2 有利于培养学生关于美的概念}

数学文化的内涵非常丰富, 所以教师在对学生进行 数学教学时, 应该对数学知识进行深入的挖掘, 将数学 知识的数学文化内涵展现出来, 让学生能够感受到数学 的美, 并且自主更加深入地了解数学文化。

结语:

综上所述, 在高校数学教育中应该体现出数学文化 的价值, 并且传播数学文化, 数学文化的传播对于高校 数学教育而言也是一个非常关键的环节, 所以高校还应 该积极的探索数学文化教育实施的有效途径。

\section{REFERENCES}

[1] Zhangbo. Analysis of Mathematics Education in Colleges and Universities from the Perspective of Mathematical Culture View [J]. Mathematics Learning and Research. 2015(15)

[2] Jianchuan Chai. Practice and Thinking of Infiltrating Mathematics Culture in Calculus Teaching [J]. Curriculum education research. 2016(36)

[3] Zhijuan Zhou. On the Role of Mathematics Culture in the Cultivation of Higher Mathematics Interest [J]. Curriculum education research. 2016(29)
[4] Qinjuan Pei. Discussion on the Integration of Mathematics Culture into Higher Vocational Mathematics Teaching [J]. Mathematics Learning and Research. 2012(07)

[5] Yisong Chen. Some Thoughts on Developing Mathematics Culture Teaching in Mathematics Course of Higher Vocational Colleges [J]. Think tank age. 2018(34)

[6] Yingying Yang. Investigation and Analysis on the Present Situation of Students' Mathematics Culture Literacy in Higher Vocational Colleges [J]. Journal of Xichang University (Natural Science Edition). 2013(02)

[7] A case study of integrating mathematical culture into the course of Probability Theory and Mathematical Statistics [J].] Zhang Xuefei. Information Systems Engineering. 2018(04)

[8] Analysis of College Mathematics Education Based on the View of Mathematics Culture [J].] Wang Xi. Curriculum education research. 2015(05)

[9] Summary of Research on the Introduction of Mathematics Culture into Mathematics Classroom in Colleges and Universities [J].] Wang Siyuan. Mathematics learning and research. 2019(02)

[10] Investigation and Analysis on College Students' Mathematics Cultural Literacy in Local Universities [J].] Navy Tang. Higher science education. 2019(02)

[11] Classroom Teaching Practice Based on Probability Theory and Mathematical Statistics of Mathematics Culture [J].] Chen Xiaolin. Modernization of education. 2019(30)

[12] Probability Theory of Integration into Mathematical Culture and Case Analysis of Teaching Design of Mathematical Statistics [J].] Chen Xiaolin. Modernization of education. 2019(34)

[13] Why can mathematics culture courses "rise and last forever "_ Summary at the closing ceremony of the 3rd Conference on Mathematics culture curriculum construction [J].] Gu Pei. Journal of Mathematics Education. 2014(06)

[14] Research on Teaching Countermeasures of Mathematics Culture Curriculum from the Perspective of Diversity — A Case Study of Guiyang Preschool Teachers College [J].] Long Ling Yun. Contemporary teaching and research. 2016(10)

[15] A brief talk on how mathematics culture integrates into higher mathematics classroom [J].] Ge Yufeng. Mathematics learning and research. 2016(21) 